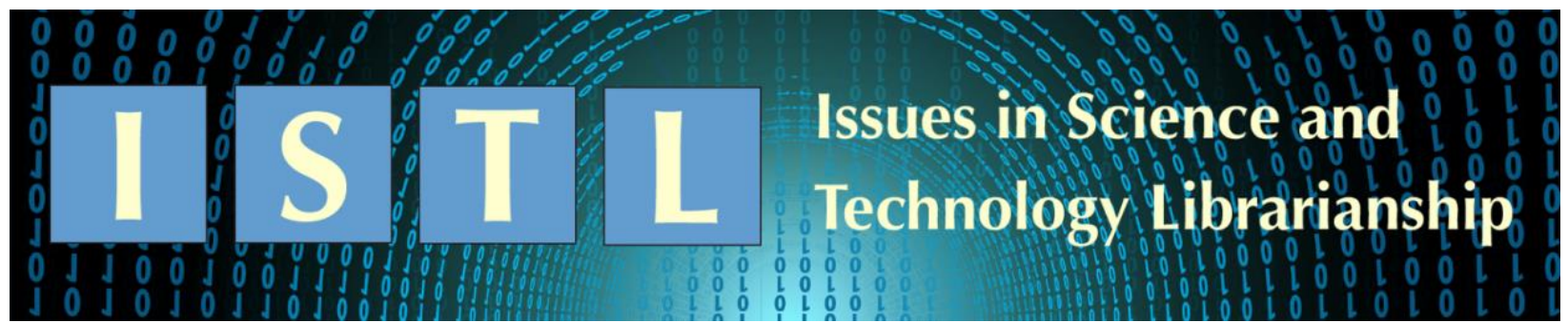

\title{
Tips from the Experts
}

\section{A Librarian and Biochemist's Experience Building a Collaborative Partnership in the Classroom and Beyond}

\author{
Alyssa Young \\ Science \& Math Librarian \\ James Madison University \\ young2ah@jmu.edu
}

\begin{abstract}
A challenge for instruction librarians is building strong, collaborative partnerships with faculty who value your expertise as both a librarian and a peer. This article discusses how a request to "help with citations" evolved into scaffolded information literacy instruction that focuses on the shared value of open resources and led to a partnership providing more opportunities to support each other.
\end{abstract}

\section{Introduction}

Librarians collaborating with faculty is an essential part of providing information literacy instruction to students in the classroom or lab. Some benefits of these collaborative partnerships include that faculty see the librarian as a colleague, allow for creativity in the lessons, and participate in ongoing conversation and feedback (Díaz \& Mandernach 2017). Building strong, collaborative partnerships between librarians and faculty can take time; from learning what the course content is to understanding what the faculty wants students to gain from the library instruction, each faculty request has different views on how involved the librarian is in the classroom.

Over the past four years as a Science and Math Librarian, I have built successful partnerships with faculty that have improved the quality of information literacy instruction the students receive. By building these partnerships collaboratively with faculty, there are opportunities to learn more about each other's values. Phelps and Campbell (2012) found stronger trust between librarians and faculty when there is "a focus on communication, shared values and benefits of the relationship." One such strong, collaborative partnership that I have built is with a Biochemistry faculty member.

\section{Background}

I was approached by the faculty late in the spring semester of 2018 to discuss ways to have students in a non-lab biochemistry course create better citations. The course we discussed is a 
non-lab general biochemistry course with about 50-75 undergraduate STEM majors. It is a project-oriented, student-centered, flipped classroom that uses open, free-to-use resources instead of textbooks and utilizes the Open Science Framework (OSF) for group projects.

During our initial meeting, we discussed what he meant by "citation help". When working with departmental faculty, it is important to acknowledge that we are both coming to the conversation from different areas of expertise. Our different interpretations of "citation help" is one of these disciplinary differences. This request was less about the students learning an actual citation style and more about where the students were searching to find their sources. Through our conversation it became clear that the faculty member was looking for better quality of the sources and a better search process from the students. This was an exciting development. While it is perfectly fine to teach solely on how to create citations using a citation management tool, it is invigorating to have time to dig deeper into where students find information and help them evaluate sources. That first meeting helped us find a common language and gain a better understanding of the problem.

After establishing a common understanding, we spoke about the content of the course and what I could bring to a class. We decided on three goals for the session. First, we wanted students to refine their information literacy skills they learned in general chemistry courses to better find, evaluate, and synthesize biochemical information. From there, we wanted students to use reliable, free, and open resources and understand their value in the biochemical field. Finally, we wanted students to have a better understanding of the whole scientific research process. We felt that by discussing how scientific information is created and disseminated, students would understand the importance of utilizing reliable resources efficiently and make more concrete connections between researching and writing.

This request for better citations built the foundation to provide information literacy skills to a course and opened doors to have more in-depth conversations with students on topics such as the use of open science and the scientific publication process.

\section{Course Evolution}

Over the past six semesters, the faculty member and I have adjusted library instruction based on our conversations, student feedback, and external factors affecting the course.

\section{In the beginning}

I presented one library instruction class the first semester. Prior to the class, I prepared a video for students to watch about open resources that are useful in searching the biochemistry literature. These resources include PubMed UniProt, Research Collaboratory for Structural Bioinformatics (RCSB) Protein Databank, and Google Scholar. Showing the video ahead of class allowed time for in-class activities and discussion. At the beginning of class, I shared five questions through an online, audience response system, Socrative, to use as an assessment of the pre-class videos. I then had students complete a Google Form activity and used their responses as points of discussion throughout the class. The activity led the students step by step through finding articles using the resources they learned about in the pre-class video and introduced them to the citation management tool Mendeley. During that part of the activity, we discussed the importance of organizing their sources and students learned how to connect Mendeley to OSF, the tool they use to store their group projects. 
After the first semester, in the fall of 2018, the faculty and I reflected on how the information literacy class impacted the course and what we could improve. In this reflection, he shared the pre-assessment and post-assessment of student's comfort level in areas where library instruction was involved (Figure 1). Students were more comfortable with these skills after taking the course. The faculty also shared that he noticed a large difference in the quality of sources in their projects, recognizing that this intervention made a difference.

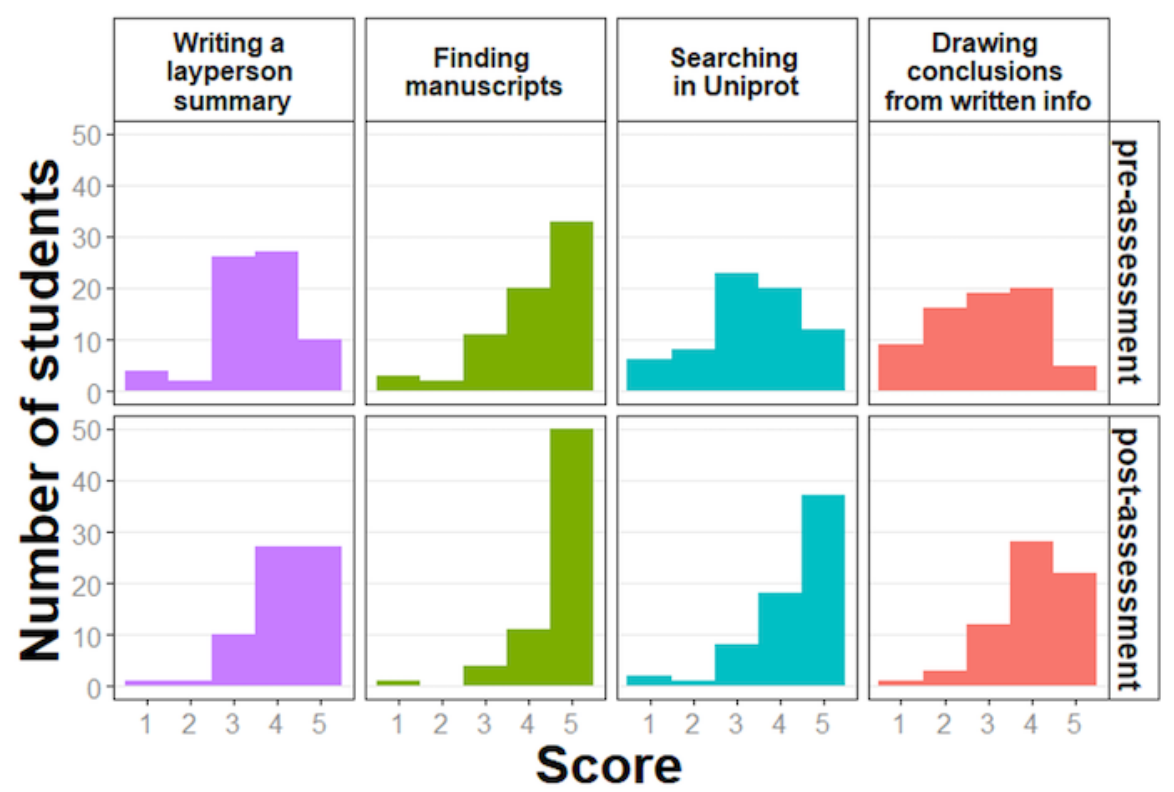

Figure 1. Fall 2018 pre-assessment and post-assessment of student's comfort level where a score of $5=$ Could perform the task with almost no supervision or guidance and a score of $1=$ Could perform the task with step-by-step guidance from the instructor

Having seen positive change in the students' work, we decided that adding a second library instruction session to the course would be beneficial. This class session takes place later in the semester and focuses on how to navigate through the scholarly literature efficiently and effectively by using the references within a paper and following where papers have been cited once published. As with the first class, we use a flipped classroom model. The students watch a video prior to class and utilize a Google Form activity with discussion throughout our in-person meeting.

The faculty member and I met after the semester to reflect on our successes and discuss further ways to improve the classes. He saw continued improvements in where students are finding their sources and the format of their citations. The pre- and post-assessments for the entire course also indicated that the students became more comfortable finding and using biochemistry literature. While this version of the pre- and post-assessments had questions that focused on information literacy, we worked together to reword and improve the questions to better align them with the targeted information literacy goals and learning outcomes of the course (James Madison University Libraries 2017; Figure 2). These goals and learning outcomes are adapted from the ACRL Framework for Information Literacy for Higher Education. We received IRB approval to use those assessments for future research. As we continued to work with one another, our trust grew and we thought of other ways to work with each other and draw on our respective expertise to benefit the students. 


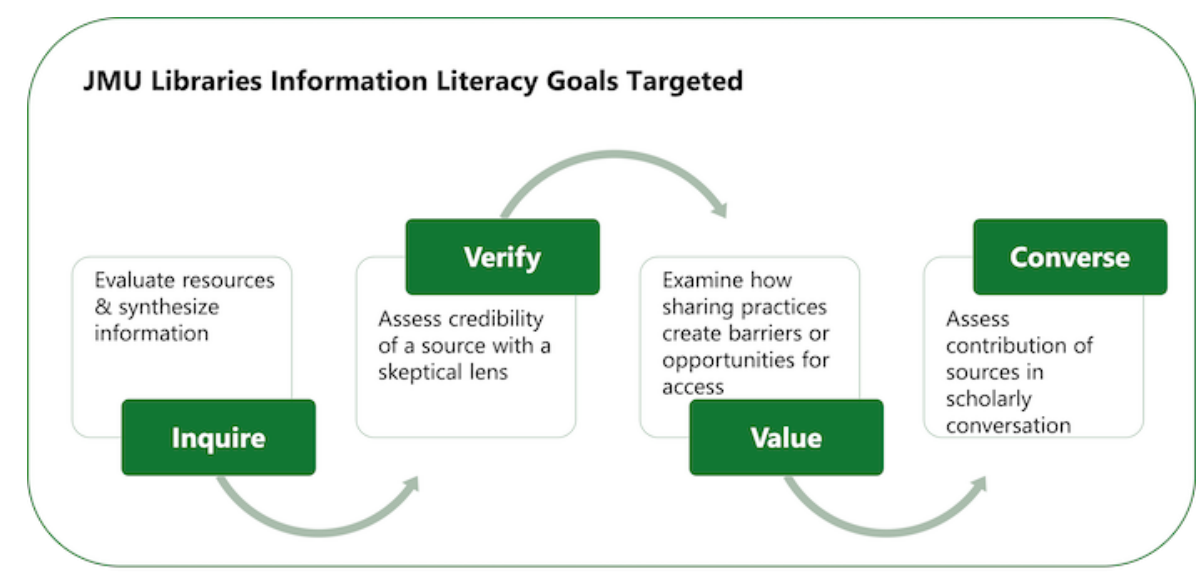

Figure 2. Goals and learning outcomes adopted in the class that align with the course pre- and post- assessment questions on information literacy.

\section{Building Our Collaborative Partnership}

Over the year, the faculty member and I had built respect for each other's skills, knowledge, and potential. We had trust in each other that let our partnership in the classroom turn into partnerships in other aspects of our work, such as grants, presentations, and publications. We both benefited from this in regards to information and ideas. It also has allowed me to have a course where I can challenge myself and the type of instruction I provide, knowing that I have a faculty partner who will not only give me feedback on the instruction, but also provide space to take these chances. The impact of our partnership is reaching beyond students citing the literature better and continues to have a positive impact on both of our careers and how we approach our work.

As we approached our third time teaching this class, we began to better align our requirements with our learning outcomes. One change was switching out Mendeley with Zotero as the citation management tool. This stemmed from wanting to better align the tool used with the open science practices that were taking place in the course. We also decided that there was not going to be an assigned citation format for the projects. Previously, students cite sources in the Journal of Biochemistry style, one that most students had never used before. This created less stress for students as they no longer had to adjust to a citation format they might not have used in the past.

During the fourth semester's course we expanded our topics to intentionally discuss access and scholarly communication topics during the first library instruction class. While the course uses an open textbook and students are taught how to use open scientific databases, we never explained the reason why or discussed what makes something open. Embedded in this discussion, we provide the students a glimpse into how these scientific papers are published, what process a scientist goes through, and how it is changing. We added discussion about reproducibility in the sciences into the second library instruction class. With this, we shifted the focus of an in-class activity about finding and evaluating articles to a discussion of open resources, reliability of scientific papers, and the publishing process. This conversation is shaped by questions students answer prior to class, and shifts during the class depending on what topics interest them. I adapted information on open access and scholarly communications into other classes, providing more depth to the information students are searching in databases.

Along with this change, we had planned a third visit that would have discussed the application of biochemistry and the relation to the resources that we had covered. This third class did not take 
place because of a shift to online learning during the COVID-19 pandemic in the spring semester of 2020.

\section{Readjusting and Continuing Ahead}

The faculty member and I met again to discuss what approach would be beneficial to use for online instruction during a shortened summer term and plan for an online fall class. Given the pandemic-created stressors on both the students and faculty, we decided to pause the pre- and post-assessments. This shift to online instruction for the summer meant there was no synchronous classroom time with the librarian. Instead, I provided the videos I had used previously and included an introduction video about myself and how I can help students with their research.

Fall 2020, while still online due to COVID-19, gave us a full semester and time for me to visit virtually twice. The topics of the two instruction classes were like the previous year but included some additional videos and additional content to expand the conversations. The changes in the conversation included a focus on the bias against underrepresented populations in publishing and research funding in the sciences. This topic connected well with the other points brought up previously in the conversations about publishing.

The changes made over the years have brought meaningful conversations with both the faculty and the students in the course. The instruction for this course has always been thoughtful and continues to evolve to align not only with the ACRL Framework or biochemistry skills but where our own values fall in the scientific publication process.

\section{Observations of Student Skills}

In many of the one-shot instruction sessions I have taught, the focus is on how to use a database but not the "why" of the research process. The way this course is set up flips this around, having students learn the "why" in order to learn the "how". By listening to student feedback and being willing to change things, we have been able to improve the research projects in this course to better facilitate the students' learning. We have observed students' information literacy skills become more refined over the semester, developing a better understanding of where to search for biochemistry information both in databases like PubMed and on the web.

The emphasis on open resources throughout this course highlights many that are available on the web and which often come up when students do an internet search for a protein. While these sources are readily available, students might not know how to use them. By providing instruction and discussion around open resources in the context of finding relevant and quality resources, students have a better understanding and are more comfortable using those resources. Through the iterations of this class, we have observed how students connect with the information we present and reflect on these observations.

We also have seen students enthusiastically engage in the conversations about the publication process and discussions about the quality of research. Students ask questions about how researchers publish their findings, where they publish, and develop a deeper understanding of the evaluation process when choosing articles. This is a highlight of the classes. The discussion is never the same and goes from straightforward questions about how one publishes to the more nuanced areas of publishing, including topics on authors citing their own work, issues with using peer review to evaluate quality, or how race and gender affect both funding and publishing. 


\section{Observations of Librarian-Faculty Partnership}

The partnership that I have built with the instructor of this course has given me both freedom and guidance. There is clear acknowledgement that I am an expert in my field and an asset to student learning. This has given me the freedom to take the information about the course and create the content that I felt best fit. We can support each other, drawing on our own experience and expertise to provide the best instruction.

We also have created a trusting partnership that allows us to reflect on and improve our teaching. In working with the faculty member, I continue to grow and learn other ways to engage with students in the classroom. The quality of instruction is high because of this partnership. I am not merely a guest; I have input and a say about how information literacy instruction blends with the course content.

\section{Next Steps}

We have started to formally assess students' understanding and comfort with library activities and resources in the course. This data will give us a better understanding of what students are getting from the library instruction. While we see anecdotal improvements, we look forward to seeing the assessment data collected over the semesters. We have plans to develop lessons and activities that engage students in open access research projects and allow them to build information literacy skills in general biochemistry. We hope to gather the resources that we use in this course to share with others so other general biochemistry lecture courses can reuse or build on our materials.

Over the years, we have built a strong foundation to our collaborative partnership through open communication, shared values, and trust. We are at a place where we can make minor tweaks to this specific biochemistry course by triangulating feedback between us and the students. We can now start to focus some attention on related projects and classes that continue to challenge us to be our best as instructors while still sticking to our values as individuals.

\section{Final Advice}

This type of partnership takes time. For those who want to cultivate similar partnerships with instructors, I have recommendations based on this experience.

First, be open to new requests and listen to what the instructor is asking. Due to jargon in different fields, the request could be something totally different than you originally think. For me, this lesson was that an instruction request for citation help was so much more than just teaching a specific citation format. However, I would not have known that if I didn't take the time to ask questions and get a better understanding of what problems the faculty was seeing in class.

Next, when building the partnership, make sure you are seen and respected as an expert. If your knowledge and skills as a librarian are not acknowledged, it could potentially be hard to build the trust that leads to taking risks and trying new things out in the classroom. After trying and failing to be seen as an expert, it might be better to try to find another instructor who does respect you as an expert.

Lastly, when you do find instructors that value your expertise, do not be afraid to try out new things both inside and outside of the classroom to further strengthen your skills as a librarian. 
This might include trying out a different style of teaching, or teaching about something you think could help the students that maybe you have not done before. For me, this was having thoughtful conversations about scientific publishing with students. Having time to discuss this in one class led to me feeling more comfortable talking about this topic in other classes. Trying new things can also include working on scholarship projects with the instructor. This can lead to interdisciplinary projects that disseminate information about how librarians work with instructors- potentially leading instructors to realize that they can ask their librarian for help!

\section{Acknowledgements}

The author wants to thank Chris Berndsen for the opportunity to build this partnership and continue to support one another in our work.

\section{References}

Díaz, J. O. \& Mandernach, M. A. 2017. Relationship building one step at a time: Case studies of successful faculty-librarian partnerships. Portal: Libraries and the Academy 17(2): 273-282. DOI: $\underline{10.1353 / \text { pla.2017.0016. }}$.

James Madison University Libraries. JMU information literacy goals [Internet]. Harrisonburg (VA); 2017. Available from: https://cdn1.lib.jmu.edu/wpcontent/uploads/JMULibrariesInformationLiteracyGoals.pdf.

Phelps, S. F. \& Campbell, N. 2012. Commitment and trust in librarian-faculty relationships: A systematic review of the literature. The Journal of Academic Librarianship 38(1): 13-19. DOI: 10.1016/j.acalib.2011.11.003.

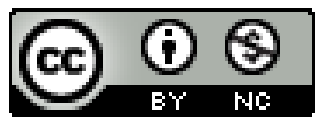

This work is licensed under a Creative Commons Attribution 4.0 International License. 